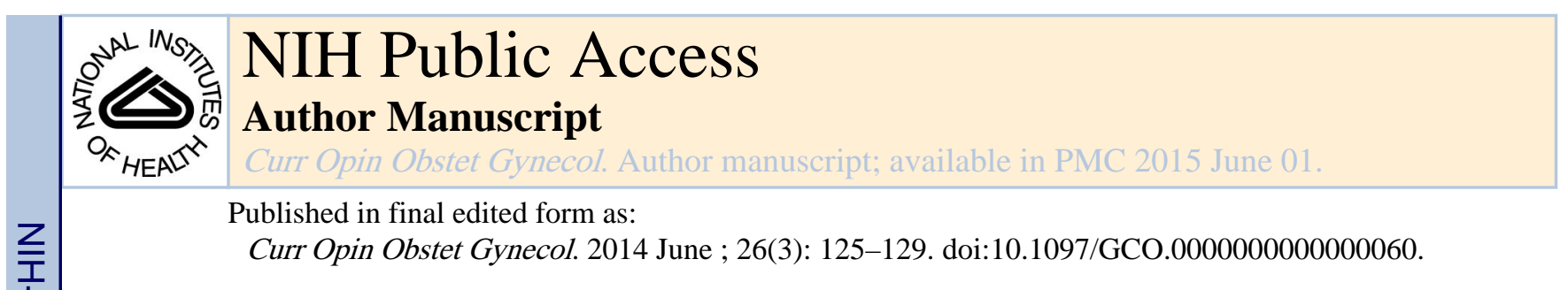

\title{
Use of fertility drugs and risk of ovarian cancer
}

\author{
Brenda Diergaarde ${ }^{a}$ and Michelle L. Kurta ${ }^{b}$ \\ aDepartment of Epidemiology, Graduate School of Public Health, University of Pittsburgh, and \\ University of Pittsburgh Cancer Institute, Pittsburgh, PA, USA \\ ' The Ohio State University Comprehensive Cancer Center, Columbus, OH, USA
}

\begin{abstract}
Purpose of review-To highlight recent research and insights into the relationship between fertility drug use and ovarian cancer risk.
\end{abstract}

Recent findings-Results from two large case-control studies provided further evidence that fertility drug use does not significantly contribute to risk of ovarian cancer among the majority of women when adjusting for known confounding factors. However, questions regarding the effect on certain subgroups, including long-term fertility drug users, women who remain nulligravid after fertility treatment, women with $B R C A 1$ or $B R C A 2$ mutations, and borderline ovarian tumors, still remain. In addition, it may currently just be too early to determine whether there is an association between fertility drug use and ovarian cancer risk given that many of the exposed women are only now beginning to reach the ovarian cancer age range.

Summary-Whether use of fertility drugs increases the risk of ovarian cancer is an important question that requires further investigation, in particular given the large number of women utilizing fertility treatments. Fortunately, results from recent studies have been mainly reassuring. Large well-designed studies with sufficient follow-up time are needed to further evaluate the effects of fertility treatments within subgroups defined by patient and tumor characteristics.

\section{Keywords}

Fertility drugs; infertility; ovarian cancer; risk

\section{INTRODUCTION}

In 2013, there are expected to be approximately 22,240 incident cases of ovarian cancer and 14,030 deaths due to ovarian cancer in the United States [1]. Ovarian cancer is a complex, multifactorial disease that, unfortunately, is often detected at a late stage; the majority of ovarian cancer cases are diagnosed with regional or distant disease when 5-year survival rates are $72 \%$ and $27 \%$, respectively [2]. There is a pressing need to identify women at increased risk for ovarian cancer as well as to identify disease-related early symptoms as this

Corresponding author: Brenda Diergaarde, UPCI Research Pavilion - Suite 1.16, 5117 Centre Avenue, Pittsburgh, PA 15213, USA; diergaardeb@upmc.edu; phone: +1-412-623-5891.

Conflicts of interest

The authors have no conflicts of interest to report. 
may result in the development of strategies that help prevent and/or lead to earlier detection of the disease. Fertility drug use has increased markedly in developed countries and is expected to increase further due to more and more women postponing attempts to become pregnant until after 35 years of age [3]. Use of ovulation-inducing drugs has been hypothesized to increase the risk of several cancers, including ovarian cancer, and there has been concern about the long-term effects of fertility drugs ever since they were first prescribed. However, despite concerns about potential negative side effects and the growing number of women utilizing fertility drug treatments, the independent effects of fertility drug use on risk of ovarian cancer have remained poorly understood. This review highlights recent research and insights into the relationship between fertility drug use and ovarian cancer risk.

\section{TWO THEORIES}

Nulliparity, late onset of menopause, and infertility are some of the factors known to be associated with an increased risk of ovarian cancer [4-12], while oral contraceptive use and breast feeding have been reported associated with a decreased risk [12-18]. Two theories, the "incessant ovulation" theory and the "elevated gonadotropin levels" theory, have been proposed to explain the mechanisms by which these factors affect risk of ovarian cancer. According to the so-called "incessant ovulation" theory, the repeated damage and subsequent repair cycles that occur during ovulation on the epithelial surface of the ovary contribute to DNA damage and so increase risk of ovarian cancer [19-22]. The consistent protective effect observed with factors that reduce the number of lifetime ovulations such as pregnancy and breastfeeding support this theory. In addition, the fact that chickens, a species of incessant ovulators, are found to have an increased risk of ovarian cancer supports this theory as well [23]. The "elevated gonadotropin levels" theory, hypothesizes that exposure to high levels of circulating pituitary gonadotropins, which stimulates the ovarian surface epithelium and so increases the risk of malignant changes, plays an important role in the development of ovarian cancer [24,25]. The decreased risk of ovarian cancer associated with each additional pregnancy and oral contraceptive use supports this theory. Infertility increases risk of ovarian cancer according to these theories because infertile women are less likely to reduce their lifetime number of ovulations by becoming pregnant and breastfeed. In addition, they may also have shorter periods of oral contraceptive use with longer time attempting to become pregnant. It should be noted though that the link with ovarian cancer may also be (in part) due to pathologic conditions associated with infertility. That is, an anomaly of the ovaries may result in infertility as well as an increased risk of cancer. Importantly, the two theories also suggest that use of fertility drugs, which stimulate ovulation and create a condition of high gonadotropin levels, may increase the risk of ovarian cancer. Moreover, based on this, use of fertility drugs would in particular be a concern for infertile women who do not get pregnant despite using ovulation-inducing drugs.

\section{FERTILITY DRUGS}

Fertility drugs promote maturation of multiple follicles and, consequently, multiple ovulations by increasing gonadotropin levels. Commonly prescribed fertility drugs are 
clomiphene citrate, a selective estrogen receptor modulator with chemical properties similar to tamoxifen that is often the first choice for treating infertility and has been around since the early 1960s, and gonadotropins such as human menopausal gonadotropin (hMG), follicle stimulating hormone (FSH), human chorionic gonadotropin (hCG) and gonadotropin releasing hormone $(\mathrm{GnRH})$. These drugs can be used alone or in combination depending on the cause of infertility and the treatment protocol used. Fertility drugs are also an important part of the treatment when utilizing assisted reproductive techniques such as in vitro fertilization (IVF). In particular gonadotropins are often used in conjunction with IVF. IVF has been used to help women become pregnant since the late 1970s.

\section{EARLIER STUDIES}

In the 1990s, several epidemiological studies, including a meta-analysis of 12 case-control studies, reported an association between use of fertility drugs and the development of ovarian cancer [26-28]. These publications raised substantial concern regarding the safety of ovulation-inducing drugs and prompted multiple other investigations. Several subsequent case-control and cohort studies did not provide evidence of an increased risk of ovarian cancer with the use fertility drugs [29-34]. However, concern regarding potential side effects of fertility drugs remained after other studies reported that women who were treated with fertility drugs for more than 12 cycles had an increased risk of ovarian cancer $[35,36]$. In addition, results from several of these earlier studies indicated that women who remained nulligravid after fertility treatment may be at increased risk for ovarian cancer and also that fertility drugs may preferentially increase the risk of borderline ovarian tumors [2628,32,37-40]. Results from the few earlier studies that examined the relationship between IVF treatment and risk of ovarian cancer have been conflicting as well, with some reporting no link between IVF treatment and ovarian cancer risk [41-44], while others found an increased risk of ovarian cancer in IVF users [45-47*]. In the largest study to date, involving 77 cases that developed in a Dutch cohort with a median follow-up of 15 years, a significantly increased risk was observed for both invasive and borderline ovarian cancer cases $\left[47^{*}\right]$.

\section{RECENT STUDIES}

Results from two recent case-control studies conducted in the United States provide further evidence that fertility drug use does not significantly contribute to risk of ovarian cancer among the majority of women when adjusting for known confounding factors [48*,49*].

Both studies observed no association between fertility drug use and overall risk of ovarian cancer. Kurta et al. used data from the Hormones and Ovarian Cancer Prediction (HOPE) study [48*]; Asante et al. used data from the Mayo Clinic Ovarian Cancer study [49*]. Strengths of both studies include a relatively large sample size and the availability of detailed reproductive and medical histories of study participants. Importantly, the ability to stratify and adjust for factors linked to ovarian cancer risk allowed the investigators to disentangle risk associated with these factors from risk associated with fertility drug use. Similar to previous reports, subgroup analyses in the HOPE study did find a statistically significant increased risk of ovarian cancer for use of fertility drugs among women who, despite seeking medical attention for infertility, remained nulligravid. Neither study

Curr Opin Obstet Gynecol. Author manuscript; available in PMC 2015 June 01. 
observed a significant association between fertility drug use and risk of borderline ovarian tumors.

Several recent studies have focused specifically on the effects of exposures received during IVF treatment on risk of ovarian cancer [50*,51*,52*]. In a cohort of 87,403 women treated for infertility in Israel, 45 ovarian cancers were identified after a mean follow-up of 8 years. Results showed some evidence of increasing risk of ovarian cancer with number of IVF cycles [50*]. However, possibly due to a relatively short follow-up period and small numbers, none of the associations observed was statistically significant. Stewart et al. investigated the effect of IVF treatment on risk of borderline ovarian tumors in an Australian cohort consisting of women seeking treatment for infertility between 1982 and 2002 [51*]. Mean follow-up was 17 years and the cohort included 31 borderline ovarian tumors. IVF treatment was found associated with a significantly increased rate of borderline ovarian tumors in univariate as well as adjusted (for age, calendar year, and socio-economic status) analyses. The investigators specifically discuss the potential of surveillance bias in their paper and note that women treated with IVF were not diagnosed significantly sooner or at a younger age than women not treated with IVF. The same cohort was used to examine the effect of IVF treatment on risk of invasive ovarian cancer, reported in a separate publication [52*]. Thirty-eight women in the cohort were diagnosed with ovarian cancer. IVF treatment was not significantly associated with overall risk of invasive ovarian cancer. In analyses stratified by parity, there was some evidence of a more pronounced effect of IVF treatment in women who did not give birth. However, none of these associations was statistically significant either.

To derive a larger number of ovarian cancer cases, Siristatidis et al. conducted a metaanalysis of 9 cohort studies involving in total 109,969 women who received IVF treatment of whom 76 were diagnosed with invasive ovarian cancer [53]. None of the recent studies discussed above were included, all included studies were published earlier. All included studies reported comparisons with the general population in their original publication but only four reported comparisons of IVF treated with non-IVF treated infertile women. Also, follow-up time in most of the studies was $<10$ years. Combined analysis with the general population as reference group showed a statistically significant association between IVF treatment and risk of invasive ovarian cancer. However, no significant associations were observed when non-IVF treated infertile women were used as reference group.

\section{COMPLICATIONS AND LIMITATIONS}

Establishing the relationship between fertility drug use and ovarian cancer risk is complex due to the fact that infertility itself increases the risk of ovarian cancer [9-12]. Moreover, use of fertility drugs correlates highly with many other factors that affect ovarian cancer risk such as cause of infertility, parity and use of oral contraceptives, which further complicates teasing out the contribution of fertility treatments.

Many of the studies that attempted to evaluate the link between fertility drug use and ovarian cancer have been hindered by methodological limitations which may explain the conflicting results. The case-control studies often included only small numbers of study participants 
who had been exposed to fertility drugs and relied on participant reports of drug use, which can be imprecise and affected by case-control status. The cohort studies often had small numbers of ovarian cancer cases and short follow-up times. In addition, many studies lacked information on cause of infertility (or indication for fertility drug use), did not have appropriate comparison groups, and or were unable to control for other important reproductive factors known to affect ovarian cancer risk (such as parity) due to either small numbers or absence of relevant data. More recent studies that have overcome some of these limitations reported no association between fertility drug use and overall ovarian cancer risk. However, questions regarding the effect on certain subgroups, including long-term fertility drug users, women who remain nulligravid after fertility treatment, women with $B R C A 1$ or $B R C A 2$ mutations, and borderline ovarian tumors, still remain.

Regarding borderline ovarian tumors, results from both earlier and more recent studies suggest that fertility drugs may specifically increase the risk of borderline ovarian tumors. Borderline ovarian tumors are low-grade ovarian malignancies with an indolent disposition which, unlike invasive ovarian tumors, do not invade the underlying ovarian stroma [54]. They are more likely to be diagnosed in women of reproductive age than invasive ovarian tumors [55], and have a better prognosis [56]. It has been speculated that the observed association with borderline ovarian tumors could be due to fertility drugs inducing growth in existing indolent tumors. Alternatively, the reported findings may not be causal but rather simply reflect more intensive medical surveillance among infertile women.

One of the largest problems currently might be that it may just be too early to establish whether there is an association between fertility drug use and ovarian cancer risk given that many of the exposed women are only now beginning to reach the ovarian cancer age range. Further long-term follow up of women treated with fertility drugs is necessary. This will be especially important for the evaluation of newer fertility drugs such as gonadotropins and for the assessment of IVF treatment.

\section{CONCLUSION}

Although the historic literature is inconsistent, most recent studies observed no association between fertility drug use and risk of ovarian cancer and have been primarily reassuring. However, some have suggested possible risk increases among women who despite fertility drug use remain nulligravid, and those developing borderline tumors. In addition, information on the effects of long-term fertility drug use and the effects of fertility treatment on women who have a $B R C A 1$ or $B R C A 2$ gene mutation is currently scarce. Given the large number of women utilizing fertility treatment, it is essential to continue to monitor and further clarify the effects of fertility drug use on ovarian cancer risk so that health care providers and women seeking treatment can make better informed decisions. Large welldesigned studies that have sufficient follow-up time and consider cause of infertility, treatment details (such as number of cycles, dose and type(s) of fertility drug used) and other potential confounding factors (such as parity, oral contraceptive use and family history) are needed to evaluate the effects of fertility treatment within subgroups defined by patient and tumor characteristics. 


\title{
Acknowledgments
}

\author{
None. \\ Financial support: This work was supported by National Institutes of Health grants P30 CA047904 and R01
} CA095023.

\section{REFERENCES AND RECOMMENDED READING}

Papers of particular interest, published within the annual period of review, have been highlighted as:

* of special interest

** of outstanding interest

1. Siegel R, Naishadham D, Jemal A. Cancer statistics, 2013. CA Cancer J Clin. 2013; 63(1):11-30. [PubMed: 23335087]

2. Howlader, N.; Noone, AM.; Krapcho, M., et al. SEER Cancer Statistics Review, 1975-2010. National Cancer Institute; Bethesda, MD: http://seer.cancer.gov/csr/1975_2010/, based on November 2012 SEER data submission, posted to the SEER web site, April 2013

3. Wysowski DK. Use of fertility drugs in the United States, 1973 through 1991. Fertil Steril. 1993; 60(6):1096-8. [PubMed: 7902301]

4. Titus-Ernstoff L, Perez K, Cramer DW, et al. Menstrual and reproductive factors in relation to ovarian cancer risk. Br J Cancer. 2001; 84(5):714-21. [PubMed: 11237375]

5. Vachon CM, Mink PJ, Janney CA, et al. Association of parity and ovarian cancer risk by family history of breast or ovarian cancer in a population-based study of postmenopausal women. Epidemiology. 2002; 13(1):66-71. [PubMed: 11805588]

6. Tung KH, Goodman MT, Wu AH, et al. Reproductive factors and epithelial ovarian cancer risk by histologic type: a multiethnic case-control study. Am J Epidemiol. 2003; 158(7):629-38. [PubMed: 14507598]

7. Braem MG, Onland-Moret NC, van den Brandt PA, et al. Reproductive and hormonal factors in association with ovarian cancer in the Netherlands cohort study. Am J Epidemiol. 2010; 172(10): 1181-9. [PubMed: 20861144]

8. Tsilidis KK, Allen NE, Key TJ, et al. Oral contraceptive use and reproductive factors and risk of ovarian cancer in the European Prospective Investigation into Cancer and Nutrition. Br J Cancer. 2011; 105(9):1436-42. [PubMed: 21915124]

9. Risch HA, Marrett LD, Howe GR. Parity, contraception, infertility, and the risk of epithelial ovarian cancer. Am J Epidemiol. 1994; 140(7):585-97. [PubMed: 7942759]

10. Brinton LA, Lamb EJ, Moghissi KS, et al. Ovarian cancer risk associated with varying causes of infertility. Fertil Steril. 2004; 82(2):405-14. [PubMed: 15302291]

11. Mosgaard BJ, Lidegaard O, Andersen AN. The impact of parity, infertility and treatment with fertility drugs on the risk of ovarian cancer. A survey. Acta Obstet Gynecol Scand. 1997; 76(2): 89-95. [PubMed: 9049278]

12. Tworoger SS, Fairfield KM, Colditz GA, et al. Association of oral contraceptive use, other contraceptive methods, and infertility with ovarian cancer risk. Am J Epidemiol. 2007; 166(8): 894-901. [PubMed: 17656616]

13. Beral V, Doll R, Hermon C, et al. Ovarian cancer and oral contraceptives: collaborative reanalysis of data from 45 epidemiological studies including 23,257 women with ovarian cancer and 87,303 controls. Lancet. 2008; 371(9609):303-14. [PubMed: 18294997]

14. Siskind V, Green A, Bain C, Purdie D. Beyond ovulation: oral contraceptives and epithelial ovarian cancer. Epidemiology. 2000; 11(2):106-10. [PubMed: 11021605]

15. Ness RB, Dodge RC, Edwards RP, et al. Contraception methods, beyond oral contraceptives and tubal ligation, and risk of ovarian cancer. Ann Epidemiol. 2011; 21(3):188-96. [PubMed: 21109450] 
16. Danforth KN, Tworoger SS, Hecht JL, et al. Breastfeeding and risk of ovarian cancer in two prospective cohorts. Cancer Causes Control. 2007; 18(5):517-23. [PubMed: 17450440]

17. Jordan SJ, Siskind V, A CG, et al. Breastfeeding and risk of epithelial ovarian cancer. Cancer Causes Control. 2011; 21(1):109-16. [PubMed: 19779839]

18. Zhang M, Xie X, Lee AH, Binns CW. Prolonged lactation reduces ovarian cancer risk in Chinese women. Eur J Cancer Prev. 2004; 13(6):499-502. [PubMed: 15548943]

19. Fathalla MF. Incessant ovulation-a factor in ovarian neoplasia? Lancet. 1971; 2(7716):163. [PubMed: 4104488]

20. Casagrande JT, Louie EW, Pike MC, et al. "Incessant ovulation” and ovarian cancer. Lancet. 1979; 2(8135):170-3. [PubMed: 89281]

21. Godwin AK, Testa JR, Handel LM, et al. Spontaneous transformation of rat ovarian surface epithelial cells: association with cytogenetic changes and implications of repeated ovulation in the etiology of ovarian cancer. J Natl Cancer Inst. 1992; 84(8):592-601. [PubMed: 1556770]

22. Tung KH, Wilkens LR, Wu AH, et al. Effect of anovulation factors on pre- and postmenopausal ovarian cancer risk: revisiting the incessant ovulation hypothesis. Am J Epidemiol. 2005; 161(4): 321-9. [PubMed: 15692075]

23. Giles JR, Elkin RG, Trevino LS, et al. The restricted ovulator chicken: a unique animal model for investigating the etiology of ovarian cancer. Int J Gynecol Cancer. 2010; 20(5):738-44. [PubMed: 20973263]

24. Cramer DW, Welch WR. Determinants of ovarian cancer risk. II. Inferences regarding pathogenesis. J Natl Cancer Inst. 1983; 71(4):717-21. [PubMed: 6578367]

25. Mohle J, Whittemore A, Pike M, Darby S. Gonadotrophins and ovarian cancer risk. J Natl Cancer Inst. 1985; 75(1):178-80. [PubMed: 3859691]

26. Whittemore AS, Harris R, Itnyre J. Characteristics relating to ovarian cancer risk: collaborative analysis of 12 US case-control studies. II. Invasive epithelial ovarian cancers in white women. Collaborative Ovarian Cancer Group. Am J Epidemiol. 1992; 136(10):1184-203. [PubMed: 1476141]

27. Rossing MA, Daling JR, Weiss NS, et al. Ovarian tumors in a cohort of infertile women. N Engl J Med. 1994; 331(12):771-6. [PubMed: 8065405]

28. Shushan A, Paltiel O, Iscovich J, et al. Human menopausal gonadotropin and the risk of epithelial ovarian cancer. Fertil Steril. 1996; 65(1):13-8. [PubMed: 8557128]

29. Modan B, Ron E, Lerner-Geva L, et al. Cancer incidence in a cohort of infertile women. Am J Epidemiol. 1998; 147(11):1038-42. [PubMed: 9620047]

30. Brinton LA, Lamb EJ, Moghissi KS, et al. Ovarian cancer risk after the use of ovulationstimulating drugs. Obstet Gynecol. 2004; 103(6):1194-203. [PubMed: 15172852]

31. Jensen A, Sharif H, Frederiksen K, Kjaer SK. Use of fertility drugs and risk of ovarian cancer: Danish Population Based Cohort Study. BMJ. 2009; 338:b249. [PubMed: 19196744]

32. Mosgaard BJ, Lidegaard O, Kjaer SK, et al. Infertility, fertility drugs, and invasive ovarian cancer: a case-control study. Fertil Steril. 1997; 67(6):1005-12. [PubMed: 9176436]

33. Rossing MA, Tang MT, Flagg EW, et al. A case-control study of ovarian cancer in relation to infertility and the use of ovulation-inducing drugs. Am J Epidemiol. 2004; 160(11):1070-8. [PubMed: 15561986]

34. Doyle P, Maconochie N, Beral V, et al. Cancer incidence following treatment for infertility at a clinic in the UK. Hum Reprod. 2002; 17(8):2209-13. [PubMed: 12151460]

35. Brinton LA, Moghissi KS, Scoccia B, et al. Ovulation induction and cancer risk. Fertil Steril. 2005; 83(2):261-74. [PubMed: 15705362]

36. Hughes E, Collins J, Vandekerckhove P. Clomiphene citrate for unexplained subfertility in women. Cochrane Database Syst Rev. 2000(3):CD000057.

37. Ness RB, Cramer DW, Goodman MT, et al. Infertility, fertility drugs, and ovarian cancer: a pooled analysis of case-control studies. Am J Epidemiol. 2002; 155(3):217-24. [PubMed: 11821246]

38. Harris R, Whittemore AS, Itnyre J. Characteristics relating to ovarian cancer risk: collaborative analysis of 12 US case-control studies. III. Epithelial tumors of low malignant potential in white

Curr Opin Obstet Gynecol. Author manuscript; available in PMC 2015 June 01. 
women. Collaborative Ovarian Cancer Group. Am J Epidemiol. 1992; 136(10):1204-11. [PubMed: 1476142]

39. Mosgaard BJ, Lidegaard O, Kjaer SK, et al. Ovarian stimulation and borderline ovarian tumors: a case-control study. Fertil Steril. 1998; 70(6):1049-55. [PubMed: 9848294]

40. Sanner K, Conner P, Bergfeldt K, et al. Ovarian epithelial neoplasia after hormonal infertility treatment: long-term follow-up of a historical cohort in Sweden. Fertil Steril. 2009; 91(4):1152-8. [PubMed: 18371964]

41. Venn A, Watson L, Lumley J, et al. Breast and ovarian cancer incidence after infertility and in vitro fertilisation. Lancet. 1995; 346(8981):995-1000. [PubMed: 7475593]

42. Venn A, Watson L, Bruinsma F, et al. Risk of cancer after use of fertility drugs with in-vitro fertilisation. Lancet. 1999; 354(9190):1586-90. [PubMed: 10560672]

43. Dor J, Lerner-Geva L, Rabinovici J, et al. Cancer incidence in a cohort of infertile women who underwent in vitro fertilization. Fertil Steril. 2002; 77(2):324-7. [PubMed: 11821091]

44. Lerner-Geva L, Geva E, Lessing JB, et al. The possible association between in vitro fertilization treatments and cancer development. Int J Gynecol Cancer. 2003; 13(1):23-7. [PubMed: 12631215]

45. Källén B, Finnström O, Nygren KG, et al. In vitro fertilisation in Sweden: obstetric characteristics, maternal morbidity and mortality. BJOG. 2005; 112(11):1529-35. [PubMed: 16225574]

46. Yli-Kuha AN, Gissler M, Klemetti R, et al. Cancer morbidity in a cohort of 9175 Finnish women treated for infertility. Hum Reprod. 2012; 27(4):1149-55. [PubMed: 22343550]

47*. van Leeuwen FE, Klip H, Mooij TM, et al. Risk of borderline and invasive ovarian tumours after ovarian stimulation for in vitro fertilization in a large Dutch cohort. Hum Reprod. 2011; 26(12): 3456-65. Largest cohort study on the long-term effects of IVF treatment on ovarian cancer risk to date. Long median follow-up time and information available on reproductive factors and cause of infertility. [PubMed: 22031719]

48*. Kurta ML, Moysich KB, Weissfeld JL, et al. Use of fertility drugs and risk of ovarian cancer: results from a U.S.-based case-control study. Cancer Epidemiol Biomarkers Prev. 2012; 21(8): 1282-92. Large case-control study with population-based controls. Investigators collected detailed information on reproductive factors and cause of infertility, which allowed them to adjust for known confounding factors. Found no association between fertility drug use and overall ovarian cancer risk. [PubMed: 22707710]

49*. Asante A, Leonard PH, Weaver AL, et al. Fertility drug use and the risk of ovarian tumors in infertile women: a case-control study. Fertil Steril. 2013; 99(7):2031-6. Large case-control study with hospital-based controls. Had information available on important confounding factors. Reported no significant association between fertility drug use and overall ovarian cancer risk. [PubMed: 23552324]

50*. Brinton LA, Trabert B, Shalev V, et al. In vitro fertilization and risk of breast and gynecologic cancers: a retrospective cohort study within the Israeli Maccabi Healthcare Services. Fertil Steril. 2013; 99(5):1189-96. Large cohort study on the effects of IVF on breast and gynecologic cancers conducted within a large health maintenance organization in Israel that had detailed information on fertility drug exposures. [PubMed: 23375197]

$51 *$. Stewart LM, Holman CD, Finn JC, et al. In vitro fertilization is associated with an increased risk of borderline ovarian tumours. Gynecol Oncol. 2013; 129(2):372-6. Population-based cohort study on the effects of IVF treatment including all women in Western Australia seeking fertility treatment. Used routinely collected linked administrative data. [PubMed: 23385152]

52*. Stewart LM, Holman CD, Aboagye-Sarfo P, et al. In vitro fertilization, endometriosis, nulliparity and ovarian cancer risk. Gynecol Oncol. 2013; 128(2):260-4. Population-based cohort study on the effects of IVF treatment including all women in Western Australia seeking fertility treatment. Used routinely collected linked administrative data. [PubMed: 23116937]

53. Siristatidis C, Sergentanis TN, Kanavidis P, et al. Controlled ovarian hyperstimulation for IVF: impact on ovarian, endometrial and cervical cancer-a systematic review and meta-analysis. Hum Reprod Update. 2013; 19(2):105-23. [PubMed: 23255514]

54. Acs G. Serous and mucinous borderline (low malignant potential) tumors of the ovary. Am J Clin Pathol. 2005; 123(Suppl):S13-57. [PubMed: 16100867] 
55. Auranen A, Grénman S, Mäkinen J, et al. Borderline ovarian tumors in Finland: epidemiology and familial occurrence. Am J Epidemiol. 1996; 144(6):548-53. [PubMed: 8797514]

56. Cusidó M, Balagueró L, Hernandez G, et al. Results of the national survey of borderline ovarian tumors in Spain. Gynecol Oncol. 2007; 104(3):617-22. [PubMed: 17112569] 


\section{KEY POINTS}

- Early studies suggested that use of fertility drugs increased the risk of developing ovarian cancer, which raised concern regarding the safety of the drugs.

- Use of fertility drugs is highly correlated with many other factors that affect ovarian cancer risk, which complicates teasing out the contribution of fertility drug treatments.

- Results from more recent studies have been primarily reassuring; most studies observed no association between fertility drug use and overall ovarian cancer risk.

- Impact of fertility drug treatment on certain subgroups, including long-term fertility drug users, women who remain nulligravid and borderline ovarian tumors, is not yet clear.

- Because many of the women treated with fertility drugs are only now beginning to reach the ovarian cancer age range, it may just be too early to determine whether fertility drug use increases ovarian cancer risk. 